\title{
The Intention to Study Using Zoom During the SARS- CoV-2 Pandemic
}

\author{
https://doi.org/10.3991/ijet.v15i21.16777
}

\author{
Nguyen Ngoc Long, Bui Huy Khoi $(\bowtie)$ \\ Industrial University of Ho Chi Minh City, Vietnam \\ buihuykhoi@iuh.edu.vn
}

\begin{abstract}
The Covid 19 pandemic has strongly influenced different social aspects such as economic, political, cultural, and social issues. The education industry also cannot avoid the severe damage that has caused educational administrators to find out many solutions to improve the teaching and learning system during the pandemic. Zoom is one of the most effective online training tools to overcome the limitations of communications caused by social distancing in response to the Coronavirus spreading. This study uses the Theory of Reasoned Action (TRA) model combined with both Corvid 19 risk perception and online security risk perception variables to examine the intention to employ Zoom - a web-based platform - for online learning of students in a university of Vietnam. 185 students from Industrial University of Ho Chi Minh City were interviewed and data from the interview results were used to evaluate the model's hypotheses. The results show that the combination of the TRA model and risk perception is a very good choice to assess the intention to adopt Zoom for distancing learning.
\end{abstract}

Keywords-SARS-CoV-2; Zoom; COVID-19 risk perception; security risk perception

\section{$1 \quad$ Introduction}

Pandemic coronavirus disease 2019 (COVID-19), caused by the extreme acute respiratory coronavirus 2 syndrome (SARS-CoV-2), has spread to 210 countries around the world, with millions of infected patients and hundreds of thousands of deaths [1]. Due to this, all global economic activities have been stalled. Moreover, universities and educational institutions in countries affected by SARS-CoV-2 have also been closed to prevent large gatherings and, therefore, help stop the spread of the disease. The data from UNESCO [2] published on April 13th, 2020 revealed that 91,3\% (equivalent to $1,576,021,818$ people) of students in 188 countries worldwide have been affected by the closing of educational institutions. Thus, educational institutions have had to find online learning solutions for courses, examinations, and even scientific research. The question for educational managers is what tools they should use to make online teaching safe and effective for both teachers and learners. According to Store [3], 500,000 educational apps have been created and used for teaching and 
learning purposes, with the top 5 apps being Reading Eggs, Speech Blubs, Zoom, Kids Academy, and ABCmouse.com. In addition, Jackie Dove [4] also listed the best 5 educational apps in Digital Trends, one of the largest independent premium technology publishers in the world, which included Zoom, Kahoot, Seesaw, Google Classroom, and Remind. Many schools and educational institutions in Vietnam use Zoom as a virtual teaching platform. This indicates that Zoom is the most useful software for online teaching. However, the vulnerability of Zoom's security has raised concerns about the safety of online classrooms. Many articles have pointed out Zoom's disadvantages and several countries and states, such as New York [5] and Singapore [6], have begun to stop using Zoom for teaching. In contrast, there are many articles which are still defending Zoom. Bloomberg pointed out that Zoom ranked 3rd among the 500 best-performing companies in the US stock exchange market [7]. Furthermore, Archibald, et al. [8] indicated the benefits of using Zoom researchers to collect qualitative data, despite its disadvantages. Thus, due to conflicting opinions, it is necessary to objectively study the factors which affect Zoom users.

People in Vietnam and other developing countries have great demand for both Internet and online tools, such as educational apps, social network sites, and other applications $[9,10]$. These are huge markets for global technology companies, such as Facebook, Microsoft, and Google. They are also sensitive to new technologies and adapt very quickly [11]. The need to use online learning and teaching apps in these countries are increasing, and the need to understand the behavior of students in choosing online tools when applied in practice is a requirement. This issue has been researched by many scholars at different school levels, such as elementary [12-14], high school [15], and university [16]. In behavioral studies, the Theory of Reasoned Action (TRA) [17, 18], the Technology Acceptance Model (TAM) [19], and the Theory of Planned Behavior (TPB) [20] are the most widely used models to accurately evaluate the intention to use. Many studies have expanded the TRA model with specific factors to increase the effectiveness of the model in clarifying the relationships between variables which influence the use of technology. Studies on behavioral intention to adopt Internet banking have shown broader associations between the TRA and innovation diffusion theory (IDT) [21] and perceived risk [22], or between the TRA and TBP with perceived risk and benefit [23]. Kalogiannakis and Papadakis [13] used TAM in conjunction with reviewing ICT use skills (Information and Communication Technologies) to forecast the intention to adopt and use tablets into teaching practice. Xie et al. [24] employed the TRA, TBP, trust, and perceived risk to study the intention do adopt e-government services. Similarly, Awa et al. [25] combined the TRA, TPB, and TOE (Technology Organization Environment) to evaluate the adoption of ecommerce services in small- and medium-scale enterprises. However, no studies have focused on combining the TRA, TAM, or TPB with risk perception in assessing the factors that influence the adoption of educational and conference software. In this study, we use a combination of the TRA model with risk perception variables to evaluate the acceptance of Zoom for learning in Vietnamese university students. In particular, we estimate the different effects of two concepts - COVID-19 risk perception (CRP), as suggested by [26], and security risk perception (SRP) [27, 28] - on the target variables of our research model. Therefore, our study aimed to clearly explain 
the factors that influence the intention to use distance-based online learning software. This is an extremely important issue which needs to be addressed by education authorities, as more people are continuing to be infected and die from COVID-19, and the closure of all public and private educational institutions is still implemented, with no clear decisions regarding the date of reopening. In particular, this is a study that uses the TRA model in combination with risk variables to consider the behavior intention of using distance learning tools in the context of the ongoing coved 19 pandemic. Previous studies extending the TRA model only considered certain intentional behaviors in the context of society without instability, or natural disasters, or pandemics. The objective of this study was to answer the question how awareness of risks arising from social instability (in particular, awareness of the threat of COVID-19 19 disease) influences factors such as Attitude, Subjective Norms of the TRA model and how it indirectly impacts the behavior Intention to use Zoom in teaching and learning.

\section{Literature Review and Research Hypotheses}

\subsection{Intention to adopt virtual learning classroom}

Virtual learning classrooms represent the use of the Internet, hardware devices, and supporting software to create a virtual space for communication between teachers and learners. The virtual classroom was developed from the concept of distance teaching, which was first established in 1972 [29], with teaching tools as "print, electronic, mechanical, or other devices". In the late 1970s and the early 1980s, the use of computers began further promoting distance learning [30-32], which evolved in later years into a diverse virtual learning classroom [33, 34]. Online learning faces many issues that previous studies have pointed out, including class participation [35], learning perception [36], learning performance [37], learning persistence [38], and virtual classroom characteristics [39]. However, since early 2020, the rapid spread of the COVID-19 pandemic has forced many countries to close educational institutions. The use of virtual classrooms under conditions of civil unrest has been proven to be essential not only for general education but has also been recommended for physicians in affected regions where there is not enough knowledge regarding the disease and strategies for its mitigation. For example, when the Ebola began in Sierra Leone, a West African country, the health system was quickly paralyzed because doctors in other countries who were knowledgeable about the disease could not physically approach to provide immediate support. Thus, with the support of Plymouth University's Peninsula Medical School, a virtual classroom was promptly formed to train the local medical workers in Sierra Leone [40]. In addition, virtual classrooms are also recommended to create natural disease models for students, in order for them to practice dealing with difficulties associated with the disease in a virtual environment, which might also help them mitigate the effects of the disease in real life [41]. Virtual classrooms have also been widely employed for distance medical training [42]. According to statistics from the first quarter of Store [3], there are hundreds of thousands of online teaching software worldwide. Moreover, a survey concluded that 
software with a live video feed, such as Zoom, WebEx, and Skype, should be used in virtual classes, as they increase the interactions between learners and teachers [43, 44] and help provide education during the COVID-19 pandemic. One study by Archibald et al. [8] has demonstrated that Zoom users have agreed on the usefulness of using this videoconferencing platform to form and maintain better rapport between researchers, when compared with the use of non-visual software, and also indicated many other advantages, such as convenience and simplicity. Previous studies have also indicated weaknesses of live-video-call applications that can arise during classes, such as poor signal transmission, unclear audio, and images, no immediate support from the class holders, high organization costs, and limited attendance [45-47]. Levak and Son [48] also agreed that each software would give learners different experiences and managers must consider the advantages and disadvantages of each online tool when choosing which to use for online classes.

\subsection{Theories to assess intention behavior}

Many theoretical models have been used to assess behavioral intentions. The most popular models are the TRA [17], TAM [19], and TPB [20]. All three theoretical models were then further expanded by being combined with the specific elements of each field of study, to form a wide range of extension models [e.g. 21-25, 49, 50, 51]. Since its inception, the TRA has always been a favorite model for studying student behaviors in schools, both in the physical learning environment and distance learning environment [44, 52-57]. The TRA model was developed using major independent variables, including attitude, SCNs, and behavioral control, which are equivalent to the behavioral control variables in the TPB model [58]. Subsequently, the TRA model was developed into the TAM model to evaluate the technology adoption behavior, by adding the variable ATT $=\beta 1 \mathrm{EOU}+\beta 2 \mathrm{USEF}+\varepsilon[19]$, where ATT is the attitude, EOU is perceived ease of use, and USEF is perceived usefulness. The TRA has indicated that volitional control was able to affect one's intention to perform a certain behavior. That is, a person will behave in a certain way if they are willing to perform that action [20]. In some cases, although the individual's willingness played a very important role, the behavior could not be performed due to capability shortage. Thus, the TPB was created to accommodate this gap [20,59]. In Vietnam, although the population has only reached 96.96 million, there are 143.3 million registered telephone subscribers. This indicates that most Vietnamese students have enough equipment to study online using simple software such as Zoom. Therefore, perceived behavior control is a variable that may have little impact on the student's intention to use Zoom. Moreover, Zoom is a very flexible software that can be used on computers, laptops, smartphones, and tablets [8], so most students can adapt. A number of previous studies have confirmed that the TRA model and its extended models are suitable for studying behavioral intention of using online teaching tools, e.g. [13]. Many studies using TRA, TPB, or TAM also suggested extending the model by combining with various theories or variables to increase the model's performance. [60]. Moreover, most of the previous behavioral research studies were conducted in stable, disease-free conditions of society. The evaluation of factors did not take into 
account the impact of uncontrolled epidemic factors and its global spreading. Therefore, in this study, we decided to use the TRA model, while considering the two variables (attitude and SCNs), in combination with risk perception variables.

\subsection{Research hypotheses}

Zoom-class adoption intention: Measuring behavioral intention is a widely used method for assessing the final intentions and behavior of an individual. Behavioral intention is the intention of a person to act on the factors promoting or reducing the desire to accomplish that intention [20, 25]. It is used in many different contexts, such as consumer behaviors, technology adoption intentions, or teaching and learning decisions [21, 25]. It is also used to assess behavioral intent on social networking sites [61] and the intention to use mobile learning software [62]. Accordingly, the intention to adopt the Zoom classroom indicates the intention to use Zoom as a virtual classroom where teachers and students can generate mutual interactions. A study by Archibald et al. [8] has indicated that the use of Zoom has many advantages but few disadvantages. However, the factors which primarily affect the students' intention to use Zoom as a popular educational application require further research to be understood.

COVID-19 Risk Perception and Security Risk Perception: COVID-19 is an unknown and unfamiliar pandemic, which greatly amplifies community risk perception [63]. Moreover, risk perception is considered to be very difficult to understand and is affected by many factors. The cultural theory of risk perception [64] classifies people into four types, namely egalitarians, individualists, hierarchies, and fatalists. Each type has a different attitude when dealing with hazards. The theory also postulates that different cultures in various countries have different risk appetites, which is expressed in the uncertainty avoidance index or the degree to which the members of a society feel uncomfortable with uncertainty and ambiguity [65]. The theory of personality [66] assesses the different levels of risk perception among individuals with different personalities. This theory considers that there are two groups of personality traits: risk-averse (the group that likes to seek safety) and risk-loving (the adventurous group). In general, risk perception is understood as the degree to which mental recognition factors relate to potentially hazardous activities or technologies which determine the risk judgments of individuals [27, 28, 67]. In addition, the risk level measurement varies with each specific condition, and the individual decision-making process is determined by the perceived cost, benefit, damage and risk appetite [68]. Previous research took risk perception as a significant factor affecting buying decisions [69] or purchasing intention [70]. The perception of risk when purchasing certain foods increases when food safety concerns arise before that food is consumed [71]. Furthermore, when a product is consumed, the consumer's attitude is also affected by being aware of certain risk factors, such as financial, functional, social, and psychological factors, as well as overall perceived risk [72]. Bauer [73] claimed that customer transactions often indicate a certain level of risk tolerance when assessing buying intentions and expected a variety of potential consequences, such as financial losses and harm. Not long after that, Cox and Rich [74] conducted a report on the 
effect of risk perception on telephone buying behavior using two factors: whether to purchase products over the telephone or not, and which products should be ordered over the telephone. Jacoby and Kaplan [72] also showed that performance consequences are most predictive of overall perceived risk for most kinds of products. Moreover, in a study by Ulleberg and Rundmo [75], the authors showed that risk assessment is based not only on what the consumers understand about the product but also on their feelings in regards to the product. Thus, emotional differences may increase the influence of risk perception on consumer behavior during the SARSCoV-2 pandemic, people may feel that other factors, such as financial risks and functional risks, are less of a threat than the risk of developing a respiratory disease. Hence, we used the CRP variable described by Huynh [26] to distinguish it from the SRP variable [27, 28]. Accordingly, CRP refers to concern regarding the spread of disease that causes people to limit certain behaviors, such as gatherings and face-toface meetings, but also leads to the implementation of other behaviors, such as food hoarding and participating in online classes. Currently, social distancing is seen as the best course of action to prevent disease spread [76,77]. Therefore, as there has not yet been developed an effective anti-COVID-19 drug, students are concerned about going to school and tend to choose Zoom as an alternative for learning. However, too much media reporting of Zoom's security vulnerabilities, such as disclosure of user identities, personally identifying information, or unauthorized access may increase students' concerns about the SRP [78]. Thus, as these risks increase, it will reduce the intention to perform cyber-behaviors [24, 62]. Hofmann et al. [79] indicated that fear of being affected by a disease may affect the attitude and behavior of individuals. Zhang, et al. [80] also showed that increased levels of fear among people in regards to the H7N9 risk (H7N9 risk perception) also increase the poultry consumption risk perception. In this study, we also hypothesized that the higher the students' fear of COVID-19, the more they fear that the use of online tools poses a risk to the cybersecurity and online safety of virtual classrooms. Moreover, in other studies, Lee [23] and Quintal et al. [81] have shown that SRP has a negative impact on consumer attitudes when intending to consume a specific product. Thus, from the abovementioned analyses, we hypothesize the following:

H1: CRP positively affects the SRP of Vietnamese students in regards to adopting the Zoom virtual classroom.

H2: CRP positively affects the SCNs of Vietnamese students in regards to adopting the Zoom virtual classroom.

H3: CRP positively affects the attitude of Vietnamese students in regards to adopting the Zoom virtual classroom.

H4: SRP negatively affects the SCNs of Vietnamese students in regards to adopting the Zoom virtual classroom.

\subsection{Subjective norm}

The behavioral decisions or intentions of individuals are always influenced by the other people around them. As pointed out by Ajzen [59], the influence of others on the behavioral intent of a person creates a perceived social pressure to engage or not 
engage in a certain activity. Moreover, integration with the environment and being influenced by others are natural human needs, belonging to the third level (social) of the scale of Maslow's five need scales [82]. Along with the personal desire to be a member of a family and society, as well as to contribute to those around them, an individual also expects sharing and advice from those around them, and thus, are affected by their surroundings when exerting their intentions. Therefore, the SCN is understood as the influence of the people surrounding a person on their intention and decision to perform a certain behavior [83, 84]. Decisions may be influenced when one person intends to copy the behavior of another and that influence has an even stronger impact on attitudes and intentions when the people involved have a close relationship with each other. However, previous studies which evaluated the SCN have had conflicting results. For example, one study found that the SCN affects $63 \%$ on the intention to adopt hybrid electric vehicles of consumers in Saudi Arabia [85], whereas a study by Shao and Kwon [61] showed that this variable did not directly affect the intention to click nuanced social feedback systems on Facebook but strongly impacted the attitude variables. Most studies on service consumption intention have similar results. Quintal et al. [81] showed that the SCN had a positive impact on attitude when evaluating tourists' intention to visit Australia and Han et al. [86] demonstrated that the SCN has an impact on visitor attitudes in regards to hotel choices. Many other studies have also shown the impact of SCNs on buying intentions $[23,80,81,86]$. Therefore, in this study, we hypothesize that:

H5: The SCN positively affects attitudes in regards to adopting Zoom as a virtual classroom during the SARS-CoV-2 pandemic.

H6: The SCN positively affects the intention to adopt Zoom as a virtual classroom during the SARS-CoV-2 pandemic.

\subsection{Attitude}

Attitude is formed by individual assessments of the intention to perform a certain target behavior [17]. Accordingly, attitude is an aspect of an individual's beliefs regarding the desired outcomes when intending to take a certain action. Attitudes have two extremes (positive or negative) when there is an intention to perform a certain action and are composed of three factors: cognitive, affective, and conative [87]. The cognitive factor involves experience, beliefs, and opinions about a certain object of interest, the affective factor comprises feelings and imagination, and the conative factor included intended behavior. Therefore, attitudes towards behaviors are directly influenced by the cognitive, affective, and conative components [20]. Davis [19] showed that attitudes towards accepting the use of new technology always include two variables, namely perceived ease of use and perceived usefulness. This also indicates that positive student attitudes are correlated with the students' awareness of the usefulness and ease of use of Zoom. Many previous studies have demonstrated that attitude has a positive impact on buying intention variables [23, 80, 81, 88]. Hence, we hypothesize the following:

H7: Student's attitudes positively affect the intention to adopt Zoom as a virtual classroom. 
The research proposes the following research model from a theoretical perspective.

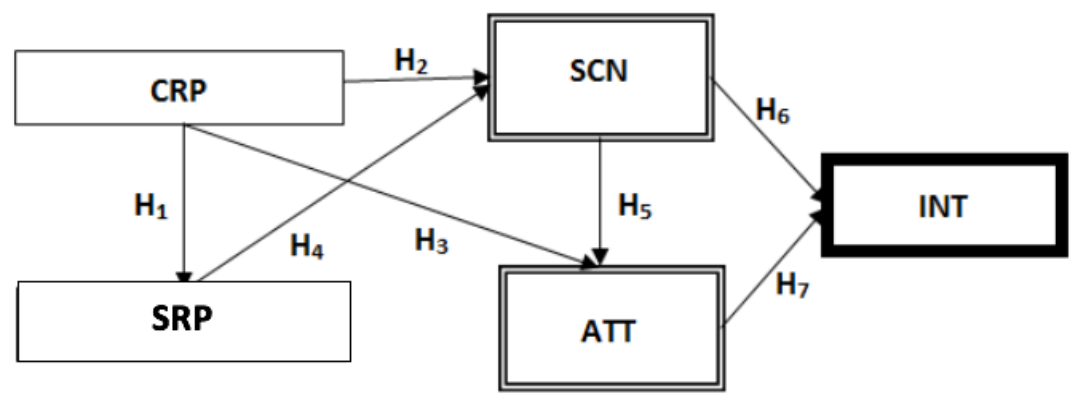

Fig. 1. Research model.

\section{$3 \quad$ Methodology}

\subsection{Sample}

In this study, questionnaires were used to obtain information for our quantitative study. The survey replies by respondents were the principal instrument to collate information. The study was carried out in 2020. Participants responded to the survey questions, which was the primary tool for data collection. The survey included questions about the status of the determinants that impacted the intention to use Zoom to study during the SARS-CoV-2 pandemic. Respondents were selected using convenient methods, and a total of 185 Vietnamese learners who use the Zoom system for educational purposes were included. Our study population consisted of $56(30.3 \%)$ men and $129(69.7 \%)$ women. Their ages, income, and qualifications are shown in Table 1 and Table 2.

Table 1. Age groups and income

\begin{tabular}{|c|c|c|l|c|c|}
\hline Age Groups & Number & Percentage (\%) & \multicolumn{1}{|c|}{ Income } & Number & Percentage (\%) \\
\hline$<18$ & 2 & 1.1 & $<5$ mill VND & 157 & 84.9 \\
\hline $18-25$ & 170 & 91.9 & $5-10$ mill VND & 21 & 11.4 \\
\hline $26-30$ & 10 & 5.4 & $11-20$ mill VND & 5 & 2.7 \\
\hline $31-40$ & 2 & 1.1 & & 2 & 1.1 \\
\hline$>40$ & 1 & 0.5 & $>20$ mill VND & 185 & 100.0 \\
\hline Total & 185 & 100.0 & Total & & \\
\hline
\end{tabular}


Table 2. Qualifications

\begin{tabular}{|l|c|c|}
\hline \multicolumn{1}{|c|}{ Qualification } & Number & Percentages (\%) \\
\hline Diploma & 5 & 2.7 \\
\hline Degree & 173 & 93.5 \\
\hline Master & 7 & 3.8 \\
\hline Total & 185 & 100.0 \\
\hline
\end{tabular}

A Likert-scale survey was used to evaluate the determinants of interest, with estimations ranging from (1) "Strongly disagree" to (5) "Strongly agree".

\subsection{Structural model assessment}

The partial least squares structural equation model (PLS-SEM) was developed over a 20 -year period, from the 1960 s to the 1980s. It was first described by Herman Wold and was further developed by this group [89]. Herman first started by advancing strategies that can resolve the least-squares relapse issues. During the 1980s, the PLS technique was utilized a few times, in the financial and sociology fields, and was then later used in the science domain, which highly acknowledged established researchers [90].

Interestingly, when using the covariance-based SEM, the PLS analysis does not display the typically conveyed factors, just as it does not aim to lessen the contrast between the watched test change and the hypothetical model fluctuation. However, PLS analysis demonstrates attempts to anticipate the factors required for the development. The accuracy of the model is assessed by re-inspecting the information using the expectation of mistakes. The PLS model does not utilize customary factual techniques for gathering information. The covariance-based SEM accepts that the information is obtained from a genuine and exact hypothetical model. The main objective of the covariance-based analysis is to fit a model, which leads to rigid calculations and requires that all included information fit the proposed model. Therefore, the covariance-based SEM must be adjusted with some measurable suspicions, such as information appropriation. Regardless, the PLS model accepts deliberate information as a set that can be deciphered and not used to fit the informational index to a hypothetical model.

We evaluated our model by using datasets regarding the intention to study using the Zoom system during the SARS-CoV-2 pandemic. The dataset contained five components from 185 learners living in Vietnam. The data processing and statistical analysis software used was Smartpls 3.0. The reliability and validity of the scale were tested by outer loading (OL), Cronbach's alpha $(\alpha)$, average variance extracted $\left(\rho_{\mathrm{vc}}\right)$, rho_A, and composite reliability $\left(\rho_{c}\right)$. The PLS-SEM was used to examine the hypotheses $[91,92]$. Cronbach's alpha $(\alpha)$ coefficient higher than 0.6 would guar-

antee the scale's reliability [93]. Moreover, if $\rho_{c}$ is greater than 0.6 , then rho_A, $\rho_{\text {vc }}$ must be greater than 0.5 and OL values must exceed 0.4. The PLS-SEM is used on ta theoretical framework. This strategy could control numerous autonomous components in any event when multicollinearity exists. The PLS model could also be used as a 
relapse model, predicting at least one ward factor from a pool with at least one free factor or it very well may be used as a way model. The PLS model could also be used for the arrangement of autonomous elements into numerous reliant variables [92].

\section{$4 \quad$ Results}

\subsection{Measurement model}

The first item evaluated was "Indicator Reliability" (see Table 3). All indicators have individual indicator reliability values that are much larger than the minimum acceptable level of 0.4 .

Table 3. Outer loading values

\begin{tabular}{|c|c|c|c|}
\hline Variable & Indicators & Meaning & OL \\
\hline \multirow{4}{*}{ ATT } & ATT1 & I like the idea of continuing to use Zoom for studying at this time. & 0.943 \\
\hline & ATT2 & Continuing to use Zoom for studying at this time is a good idea. & 0.935 \\
\hline & ATT3 & I agree with the continued use of Zoom for studying. & 0.949 \\
\hline & ATT4 & $\begin{array}{l}\text { I am satisfied with my intention to continue using Zoom for } \\
\text { studying. }\end{array}$ & 0.929 \\
\hline \multirow{4}{*}{ CRP } & CRP1 & $\begin{array}{l}\text { I feared the possibility of spreading COVID-19 when going to the } \\
\text { school directly. }\end{array}$ & 0.915 \\
\hline & CRP2 & $\begin{array}{l}\text { I feared being infected with COVID-19 when I went to the school } \\
\text { directly. }\end{array}$ & 0.904 \\
\hline & CRP3 & I am aware of the danger of a COVID-19 outbreak. & 0.825 \\
\hline & CRP4 & $\begin{array}{l}\text { Studying online through Zoom helps reduce the risk of contracting } \\
\text { COVID-19. }\end{array}$ & 0.825 \\
\hline \multirow{4}{*}{ INT } & INT1 & I intend to continue using Zoom to study in the coming days. & 0.916 \\
\hline & INT2 & $\begin{array}{l}\text { I have intended to continue using Zoom to study in the coming } \\
\text { days. }\end{array}$ & 0.925 \\
\hline & INT3 & $\begin{array}{l}\text { I look forward to continuing to use Zoom to study in the coming } \\
\text { days. }\end{array}$ & 0.929 \\
\hline & INT4 & $\begin{array}{l}\text { I will continue to learn more about Zoom and use it for studying in } \\
\text { the coming days. }\end{array}$ & 0.926 \\
\hline \multirow{4}{*}{$\mathrm{SCN}$} & SCN1 & My friends want me to continue using Zoom for studying. & 0.919 \\
\hline & SCN2 & My friends encourage me to continue using Zoom for studying. & 0.936 \\
\hline & SCN3 & My relatives supported me to continue using Zoom for studying. & 0.933 \\
\hline & SCN4 & My relatives encourage me to continue using Zoom for studying. & 0.945 \\
\hline \multirow{3}{*}{ SRP } & SRP1 & $\begin{array}{l}\text { I am concerned about the security risks associated with using } \\
\text { Zoom. }\end{array}$ & 0.875 \\
\hline & SRP2 & $\begin{array}{l}\text { There certainly are security risks when using Zoom for online } \\
\text { studying. }\end{array}$ & 0.917 \\
\hline & SRP3 & $\begin{array}{l}\text { My personal information may be exposed when I use Zoom for } \\
\text { studying. }\end{array}$ & 0.888 \\
\hline
\end{tabular}

ATT, attitude; CRP, COVID-19 risk perception; SCN, subjective norm; SRP, security risk perception; OL, outer loading.

Most OL values exceeded greater than 0.4 , as shown in Table 3. This characteristic is measured by OL on a construct, which shows that the associated indicators have 
statistical significance [92]. Therefore, if the OL value of the item was greater than 0.4 , that item will be accepted in the model.

The measurement model evaluates the reliability and validity of the variables. The $\alpha$ coefficient and $\rho_{c}$ values were used to verify the construct's reliability [94]. According to Hair Jr. et al. [92], the $\alpha$ coefficient and $\rho_{c}$ values should be greater than 0.6. However, this study found that the $\alpha$ coefficient from 0.874 to 0.955 and $\rho_{c}$ values from 0.922 to 0.967 were respectively, as shown in Table 4.

Moreover, according to Hair Jr et al. [94], the values of $\rho_{\mathrm{vc}}$ and rho_A should be greater than 0.5 . In our study, $\rho_{\text {vc }}$ from 0.753 to 0.881 and rho_A values from 0.876 to 0.955 were accepted. Therefore, the results of our study successfully establish convergent validity. Hence, the measurement model used in this study was successfully validated. The values obtained for the $\alpha$ coefficient, $\rho_{c}$, rho_A, and $\rho_{\mathrm{vc}}$ are shown in Table 4.

Table 4. The reliability and validity

\begin{tabular}{|l|c|c|c|c|}
\hline Construct & $\begin{array}{c}\text { Cronbach's alpha } \\
\text { coefficient }\end{array}$ & rho_A & $\rho_{c}$ & $\rho_{\text {vc }}$ \\
\hline ATT & 0.955 & 0.955 & 0.967 & 0.881 \\
\hline CRP & 0.891 & 0.904 & 0.924 & 0.753 \\
\hline INT & 0.943 & 0.943 & 0.959 & 0.854 \\
\hline SCN & 0.951 & 0.951 & 0.964 & 0.871 \\
\hline SRP & 0.874 & 0.876 & 0.922 & 0.798 \\
\hline
\end{tabular}

$\rho_{\mathrm{vc}}$, average variance extracted; $\rho_{\mathrm{c}}$, composite reliability.

Moreover, discriminant validity was used to validate the external consistency of the construct. The discriminant validity was evaluated based on the Fornell-Larcker criterion and the heterotrait-monotrait ratio of correlations (HTMT). According to the Fornell-Larcker criterion, the square root of the $\rho_{\mathrm{vc}}$ values should be greater than that of other constructs when moving vertically in a column. In addition, the HTMT index offers a new criterion which is useful for measuring the external consistency of the construct [94]. This criterion is used to overcome the shortcomings of the FornellLarcker criterion and cross-loadings. 
Table 5. Fornell-Larcker Criterion

\begin{tabular}{|l|l|l|l|l|l|}
\hline \multicolumn{1}{|c|}{ Construct } & ATT & CRP & INT & SCN & SRP \\
\hline ATT & 0.939 & & & & \\
\hline CRP & 0.541 & 0.868 & & & \\
\hline INT & 0.881 & 0.523 & 0.924 & & \\
\hline SCN & 0.845 & 0.506 & 0.802 & 0.933 & \\
\hline SRP & 0.048 & 0.328 & 0.053 & 0.039 & 0.893 \\
\hline
\end{tabular}

ATT, attitude; CRP, COVID-19 risk perception; INT, intention; SCN, subjective norm; SRP, security risk perception.

However, the values of the HTMT should not be greater than 1 [94]. Therefore, the constructs passed the validity test and all values obtained were within the threshold limits, as shown in Table 5 and Table 6.

Table 6. Heterotrait-Monotrait Ratio (HTMT)

\begin{tabular}{|l|c|c|c|c|}
\hline \multicolumn{1}{|c|}{ Construct } & ATT & CRP & INT & SCN \\
\hline CRP & 0.572 & & & \\
\hline INT & 0.929 & 0.557 & & \\
\hline SCN & 0.886 & 0.533 & 0.845 & \\
\hline SRP & 0.068 & 0.376 & 0.075 & 0.060 \\
\hline
\end{tabular}

ATT, attitude; CRP, COVID-19 risk perception; INT, intention; SCN, subjective norm; SRP, security risk perception.

\subsection{Structural model assessment}

After using the PLS algorithm, the structural model was evaluated to make the final decision regarding hypothesis acceptance or rejection. The path coefficient was used to verify the relationship between constructs.

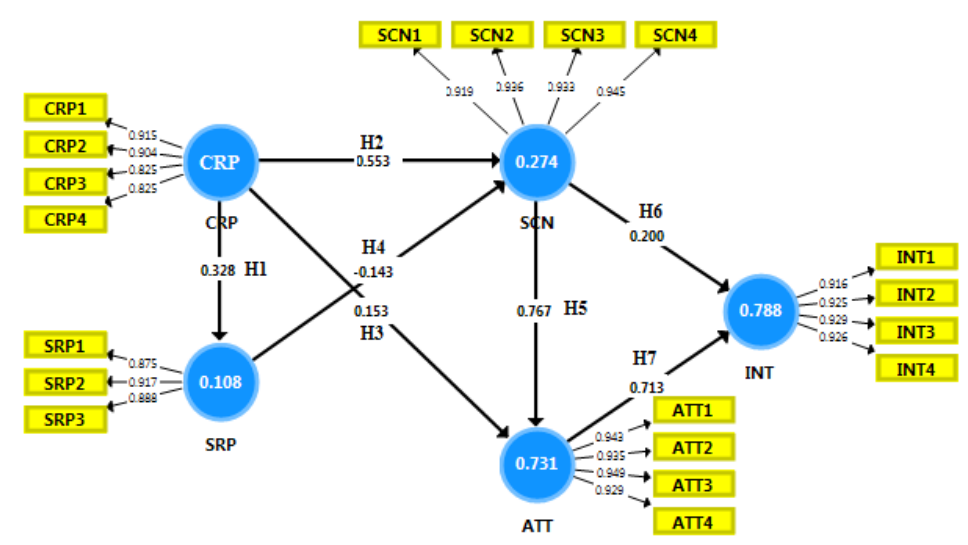

Fig. 2. Structural Model 
In other words, the PLS can be a regression model that can handle one or more dependent variables with a set of one or more independent variables, or it can be implemented as a path model. However, the bootstrapping technique has been used to run the PLS coefficient or path coefficient. The outcome of the significance level obtained by using the bootstrapping method should have t-values greater than 1.96 at a significance level of 0.05 . The present study has used the bootstrapping method on 5000 sub-samples and the results are shown in Table 7 and Figure 2. The coefficient of determination $\left(\mathrm{R}^{2}\right)$ was used to evaluate the power of the model. The value of $\mathrm{R}^{2}$ is between 0 and 1 , with higher values indicating higher determination. $\mathrm{R}^{2}$ values of $0.75,0.50$, and 0.25 , are considered high, moderate, and low, respectively. The $\mathrm{R}^{2}$ value of our model was 0.788 , which is considered high. Our results showed that all hypotheses are supported with p-values in table 7 .

Table 7. The direct relationship between constructs

\begin{tabular}{|l|c|c|c|c|l|}
\hline \multicolumn{1}{|c|}{ Hypothesis } & Beta & SD & T Values & P Values & \multicolumn{1}{c|}{ Decision } \\
\hline ATT -> INT & 0.713 & 0.088 & 8.141 & 0.000 & Acceptance \\
\hline CRP -> ATT & 0.153 & 0.037 & 4.084 & 0.000 & Acceptance \\
\hline CRP -> SCN & 0.553 & 0.058 & 9.593 & 0.000 & Acceptance \\
\hline CRP -> SRP & 0.328 & 0.092 & 3.575 & 0.000 & Acceptance \\
\hline SCN -> ATT & 0.767 & 0.038 & 20.307 & 0.000 & Acceptance \\
\hline SCN -> INT & 0.200 & 0.092 & 2.167 & 0.031 & Acceptance \\
\hline SRP -> SCN & -0.143 & 0.078 & 1.818 & 0.070 & Acceptance \\
\hline
\end{tabular}

ATT, attitude; CRP, COVID-19 risk perception; INT, intention; SCN, subjective norm; SRP, security risk perception. Note: *, $\mathrm{p}<0.1 ; * *, \mathrm{p}<0.05 ; * * *, \mathrm{p}<0.01$ (Two-Tail)

Table 8. Model fit

\begin{tabular}{|l|c|}
\hline \multicolumn{1}{|c|}{ Indicator } & Saturated model \\
\hline SRMR & 0.063 \\
\hline d_ULS & 0.745 \\
\hline d_G & 0.899 \\
\hline Chi-Square & 858.511 \\
\hline NFI & 0.801 \\
\hline
\end{tabular}

The results shown in Table 8 revealed that the Chi-square index of 858.511 was significant at the 0.05 level. The standardized root means square residual (SRMR) was a measure of the approximate model fit of the proposed research model. By convention, a model has a good model fit when the SRMR is below 0.08 [95]. The results in Table 7 show that the model had SRMR indices of 0.063 , which is lower than 0.08 . the proposed research model was well suited to the data analyzed. 


\section{Conclusion and Implications}

\subsection{Conclusion}

The main purpose of the current study is to use the traditional TRA model combined with risk perception variables to evaluate the intention of using Zoom of students during the SARS-CoV-2 pandemic. The model has achieved a very high performance when all the assumptions are supported and statistically significant. The results showed that Covid 19 perceived risk due to disease has a strong impact on subjective norms, perceived security risk, and attitude of learners. This demonstrates that the use of disease risk perception variables in the traditional TRA model is essential when measuring a specific intentional behavior. Previous studies have largely ignored the disease risk perception variable because those studies were conducted in a stable, disease-free society. Especially, this study uses two risk perception variables, each of which has a statistically significant opposite effect on the target variable. In particular, the SRP variable does not exert a significant effect on the SCN, indicating that it does not have a great contribution to the student's intention to use Zoom for online learning. Thus, our study has contributed to advances in the TRA model when combined with risk perception variables to evaluate cases of educational application adoption. Moreover, our results provide education managers with a clear, objective view of the use of the Zoom software or virtual classes for online teaching. The study also shows that software companies need to pay attention to online security when deploying live video conferencing software. On the other hand, the governments of different countries need to pay attention to communication orientation and the policies supporting the strengthening of network security systems for technology companies which have significant market development potential. This can help software companies better contribute to the development of distance education and online networking tools.

In our study, the CRP variable had a high effect on the SRP variable, suggesting that concern over disease has led to the use of online tools for learning, which has subsequently resulted in increasing concerns about network security. The reason may be the sharply increasing demand for Zoom and the fact that users could not immediately update their knowledge about security protection skills. Therefore, worrying about the spread of COVID-19 leads to network security concerns. Notably, the results of our study are consistent with those of Zhang et al [80].

The CRP variable of our models had a strong positive association with the SCN. This proves that relatives and friends of students are concerned about the threats associated with the spread of the pandemic and are, therefore, urging and encouraging them to use the Zoom app for distance learning and limit social exposure. This result is also similar to that obtained by Zhang et al. [80].

The CRP variable also significantly influences students' attitudes toward the intention to use Zoom. These results conflict with those obtained by Zhang et al. [80]. The reason is that the dependent variable of the previous study mentioned above is poultry meat consumption during the epidemic period, which was one of the main causes of contracting the H7N9 virus. That is, higher awareness in regards to risk led to a lower 
intention to consume. In contrast, our study evaluated the intention to adopt Zoom for learning in order to reduce the risk of disease transmission. Consequently, the fear of the disease spreading increased the intention to use Zoom.

The SRP variable in our study was found to have a negative effect on the SCN variable. This implies that the greater the concern for cybersecurity and privacy issues, the SCNs will have less impact on the intention to use Zoom in students. Although the impact level is not high, this result is consistent with the outcomes of previous studies $[23, \underline{81}$. Therefore, our results indicate that the risk perception variable is not one of the key factors which affect students' intention to use Zoom.

Similar to the results of previous studies, the SCN variable in our study had a strong impact on student attitudes when using Zoom [81, 86]. This proves that, in Vietnam, students are still strongly influenced by others' expectations. This may explain why Vietnamese students are still dependent on their families for resources while they are in school. However, this result may be different if the sample population was composed of people who were working.

Both the attitude and SCN variables influence the dependent variable. Moreover, these results are positively correlated with the results of previous studies $[23,80,81$, $86,88]$. The attitude and SCNs are the two key factors which affect the adoption of Zoom for learning by students, with $\mathrm{R}^{2}=78.8 \%$. Furthermore, the model employed in our study is very suitable for considering the students' intention to adopt a virtual classroom during the pandemic.

\subsection{Implications}

This study confirms that the use of the TRA model in combination with the risk perception variables accurately explains the intention to use Zoom for learning by students during the SARS-CoV-2 pandemic. The study shows that the behavioral intention research taking place in stable social conditions and taking place in the context of a society affected by the Covid 19 epidemic is completely different, the disease risk perception variables or the similar social unrest factors need to be given special attention. The study of these variables helps policymakers make the best decisions when social instability emerges. At the same time, researchers need to accept the fact that traditional models will change or may even be broken when social conditions change.

Contributions of this study also reinforce the theory that the TRA model and the risk perception variables can be used to evaluate internet-based service consumption behavior. It also provides insight which can help guide the business management and administrative decisions of educational managers, governments, and online learning software suppliers. For educational administrators, it is necessary to explain the usefulness and benefits of Zoom to students and their relatives, as well as explain the fact that Zoom is a good support software for distance teaching and learning during social unrest and provide information regarding privacy prevention. In this study, attitude greatly influenced students' intention to use Zoom. Therefore, educational authorities and institutions need to properly explain the positive and negative aspects of using Zoom to ensure uninterrupted learning and other related issues. On the other hand, 
parents of students in this age group, which almost entirely dependent on the family's financial support, should be provided with explanations regarding the benefits and negative impacts associated with the use of virtual classrooms by their children for distance learning. An important issue is that the SCN variable is not highly impacted by the SRP variable, which proves that public opinion in regards to online safety and security has a weak impact on reducing the intention of students to use Zoom. This can be easily explained by the fact that students possess little important information in their personal computers or other handheld devices, and, therefore, do not considered data security to be important. However, software suppliers need to make appropriate improvements for privacy protection functions to minimize the intrusion of strangers into the classroom which can perform negative activities. Every software can face security issues. Not only Zoom, but all other online learning software can have security holes. Moreover, rapid growth in the number of software users has always led to the rise of security concerns. Additionally, new software that attracts the attention of society will often cause competition from other software vendors. Negative posts can be proactively spread and create a negative image in the user's eyes. Therefore, enterprises that provide online video conferencing and web conferencing software should pay attention to security issues as a top priority, not only due to the security concerns of the users, but also for social media, which can diminish the useful features, advantages, and development potential of a technology company.

Another important contribution of our study is that attitude and SCNs are the main determinants of the intention to use the Zoom software for online learning. Moreover, the CRP variable was shown to have a high impact on the SCNs and attitudes of learners. This proves that when society is at risk of civil instability and requires social distancing, the demand for online learning software will increase. Governments or economic organizations should support businesses with the potential to develop useful teaching tools, such as Zoom, in order to take advantage of distance learning. This is especially important for students in poor or developing countries, where students do not yet have modern equipment or too much knowledge in regards to computer technology to access software or apps that require complex skills and manipulation features.

Limitations and future recommendations: This research has ignored the impact of media on the intention to use the Zoom software for learning. This may be an important factor because the SRP variable does not directly affect the behavior of users, but the current adverse information about this software still restricts the use of Zoom and can even prohibit it. This study initially ignores media variables because we hypothesized that SRP would highly impact students' intention to use Zoom.

Another problem refers to cultural differences in regards to using online software between Vietnamese students and students in other countries worldwide. Future research should extend the sampled population to various countries to consider the impact of cyberculture on students' intention to use online learning software in different places. This is a very necessary aspect, as the information technology available today has created a very "flat" world, with software products that are favored in one country quickly becoming of interest and being used in other countries. In particular, the demand for educational software is increasing in developing countries, 
whose economies are considered lagging but have a high percentage of people using the internet and online tools.

In addition, the government's role in the use of online tools by citizens also needs to be considered when there is social unrest, such as the ongoing SARS-CoV-2 pandemic and the need for social distancing. Future research should take in to account this variable to estimate the extent of its impact on attitudes, SCNs, and behavioral intention.

On the other hand, this study only focused on the education sector. Social distancing requires the adoption of similar videoconferencing software in many other areas, such as businesses, public administrations, and international trading. Therefore, future study populations should be extended to broader areas, such as business meetings, technical training, and so on.

\section{Conflict of Interest}

The authors confirm that there is no conflict of interest to declare for this publication.

\section{$7 \quad$ Acknowledgment}

This work was supported in part by the Industrial University of Ho Chi Minh City, Vietnam. The authors sincerely appreciate the editor and reviewers for their time and valuable comments.

\section{$8 \quad$ References}

[1] Worldometer. COVID-19 Coronavirus Pandemic [Online].

[2] UNESCO. COVID-19 Educational Disruption and Response [Online].

[3] E. A. Store. (2020, April 13). Best Educational Apps. Available: https://www.educational appstore.com/app-lists/apps-for-education

[4] A. R. Jackie Dove. (2020, The best apps for teachers and educators. Available: https:// www.digitaltrends.com/mobile/best-apps-for-teachers-education/

[5] L. Feiner. (2020, April 14, 2020). NYC education department tells principals to stop using Zoom, citing privacy concerns. Available: https://www.cnbc.com/2020/04/06/nyc-doetells-principals-to-switch-from-zoom-to-google-and-microsoft.html

[6] N. Manskar. (2020, April 14). Singapore teachers stop using Zoom after hackers crash class meetings. Available: https://nypost.com/2020/04/10/singapore-teachers-stop-usingzoom-after-hackers-crash-class-meetings/

[7] N. G. Drake Bennett (2020, April 9, 2020) Zoom Goes From Conferencing App to the Pandemic's Social Network. Bloomberg Businessweek. Available: https://www.bloomberg.com/news/features/2020-04-09/zoom-goes-from-conferencing-app -to-the-pandemic-s-social-network

[8] M. M. Archibald, R. C. Ambagtsheer, M. G. Casey, and M. Lawless, "Using Zoom Videoconferencing for Qualitative Data Collection: Perceptions and Experiences of Researchers and Participants," International Journal of Qualitative Methods, vol. 18, p. 1609406919874596, 2019. https://doi.org/10.1177/1609406919874596 
[9] M. Andjelkovic, "The future is mobile: Why developing country entrepreneurs can drive Internet innovation," SAIS Review of International Affairs, vol. 30, pp. 121-133, 2010. https://doi.org/10.1353/sais.2010.0015

[10] M. Duong, "The Formation of Network Society in Vietnam: Promise or Peril?," Asiascape: Digital Asia, vol. 6, pp. 17-34, 2019. https://doi.org/10.1163/22142312-12340100

[11] S. Persada, J. Ivanovski, B. Miraja, R. Nadlifatin, I. Mufidah, J. Chin, et al., "Investigating Generation Z'Intention to Use Learners' Generated Content for Learning Activity: A Theory of Planned Behavior Approach," International Journal of Emerging Technologies in Learning (iJET), vol. 15, pp. 179-194, 2020. https://doi.org/10.3991/ijet.v15i04.11665

[12] S. Papadakis, M. Kalogiannakis, and N. Zaranis, "Developing fundamental programming concepts and computational thinking with ScratchJr in preschool education: a case study," International Journal of Mobile Learning and Organisation, vol. 10, pp. 187-202, 2016. https://doi.org/10.1504/ijmlo.2016.077867

[13] M. Kalogiannakis and S. Papadakis, "Evaluating pre-service kindergarten teachers' intention to adopt and use tablets into teaching practice for natural sciences," International Journal of Mobile Learning and Organisation, vol. 13, pp. 113-127, 2019. https://doi. org/10.1504/ijmlo.2019.10016617

[14] S. Papadakis and M. Kalogiannakis, "Evaluating a course for teaching introductory programming with Scratch to pre-service kindergarten teachers," International Journal of Technology Enhanced Learning, vol. 11, pp. 231-246, 2019. https://doi.org/10.1504/ijtel. 2019.100478

[15] F. Soykan, "Acceptance scale of tablet computers by secondary education students: validity and reliability study," Journal of Universal Computer Science, vol. 23, pp. 1132$1146,2017$.

[16] S. Papadakis, M. Kalogiannakis, E. Sifaki, and N. Vidakis, "Access moodle using smart mobile phones. A case study in a Greek University," in Interactivity, Game Creation, Design, Learning, and Innovation, ed: Springer, 2017, pp. 376-385. https://doi.org/10.10 07/978-3-319-76908-0_36

[17] F. Ajzen, "Theory of reasoned action (TRA) in information seeking behavior and technology adoption: theories and trends," ed: IGI Global, 1980.

[18] M. Fishbein and I. Ajzen, "Belief, attitude, intention, and behavior: An introduction to theory and research," 1977.

[19] F. D. Davis, "A technology acceptance model for empirically testing new end-user information systems: Theory and results," Massachusetts Institute of Technology, 1985.

[20] I. Ajzen, "The theory of planned behavior," Organizational behavior and human decision processes, vol. 50, pp. 179-211, 1991. https://doi.org/10.1016/0749-5978(91)90020-t

[21] Y.-H. Lee, Y.-C. Hsieh, and C.-N. Hsu, "Adding innovation diffusion theory to the technology acceptance model: Supporting employees' intentions to use e-learning systems," Journal of Educational Technology \& Society, vol. 14, pp. 124-137, 2011.

[22] A. N. Giovanis, S. Binioris, and G. Polychronopoulos, "An extension of TAM model with IDT and security/privacy risk in the adoption of internet banking services in Greece," EuroMed Journal of Business, 2012. https://doi.org/10.1108/14502191211225365

[23] M.-C. Lee, "Factors influencing the adoption of internet banking: An integration of TAM and TPB with perceived risk and perceived benefit," Electronic commerce research and applications, vol. 8, pp. 130-141, 2009. https://doi.org/10.1016/j.elerap.2008.11.006

[24] Q. Xie, W. Song, X. Peng, and M. Shabbir, "Predictors for e-government adoption: integrating TAM, TPB, trust and perceived risk," The Electronic Library, 2017. https://doi. org/10.1108/el-08-2015-0141

[25] H. O. Awa, O. U. Ojiabo, and B. C. Emecheta, "Integrating TAM, TPB and TOE frameworks and expanding their characteristic constructs for e-commerce adoption by SMEs," Journal of Science \& Technology Policy Management, 2015. https://doi.org/10.11 $\underline{\text { 08/jstpm-04-2014-0012 }}$ 
[26] T. L. Huynh, "The COVID-19 risk perception: A survey on socioeconomics and media attention," Economics Bulletin, vol. 40, pp. 758-764, 2020.

[27] A. Wildavsky and K. Dake, "Theories of Risk Perception: Who Fears What and Why?," Daedalus, vol. 119, pp. 41-60, 1990.

[28] L. Sjöberg, "Factors in risk perception," Risk analysis, vol. 20, pp. 1-12, 2000.

[29] M. G. Moore, "Learner autonomy: The second dimension of independent learning," Convergence, vol. 5, p. 76, 1972.

[30] S. R. Hiltz and M. Turoff, The network nation: Human communication via computer: Mit Press, 1993. https://doi.org/10.7551/mitpress/4920.001.0001

[31] C. K. Knapper, * Expanding Learning Through New Communications Technologies: Jossey-Bass, 1982.

[32] M. G. Ryan, "Telematics, teleconferencing and education," Telecommunications Policy, vol. 5, pp. 315-322, 1981/12/01/ 1981. https://doi.org/10.1016/0308-5961(81)90039-2

[33] S. R. Hiltz, "The "virtual classroom": Using computer-mediated communication for university teaching," Journal of communication, vol. 36, pp. 95-104, 1986. https://doi.org/ 10.1111/j.1460-2466.1986.tb01427.x

[34] S. R. Hiltz, The virtual classroom: Learning without limits via computer networks: Intellect Books, 1994.

[35] M. A. Chilton, "Technology in the classroom: Using video links to enable long distance experiential learning," Journal of Information Systems Education, vol. 23, p. 5, 2019.

[36] J. A. Potts, "Profoundly Gifted Students' Perceptions of Virtual Classrooms," Gifted Child Quarterly, vol. 63, pp. 58-80, 2019/01/01 2018. https://doi.org/10.1177/001698621880107 $\underline{5}$

[37] C. Wijesooriya, J. Heales, and F. Rohde, "Evaluation of virtual learning environment characteristics in learning performance," in Proceedings of the 10th International Conference on E-Education, E-Business, E-Management and E-Learning, 2019, pp. 259263. https://doi.org/10.1145/3306500.3306535

[38] J. S. Simplicio, "Strategies to Improve Online Student Academic Success and Increase University Persistence Rates," Education, vol. 139, pp. 173-177, 2019.

[39] J. B. Arbaugh, "Republication of "Virtual Classroom Characteristics and Student Satisfaction with Internet-Based MBA Courses"," Journal of Management Education, vol. 42, pp. 533-556, 2018. https://doi.org/10.1177/1052562918770400

[40] C. Sansom, "The virtual classroom and Ebola preparedness," The Lancet Infectious Diseases, vol. 15, pp. 515-516, 2015. https://doi.org/10.1016/s1473-3099(15)70172-6

[41] N. Neulight, Y. B. Kafai, L. Kao, B. Foley, and C. Galas, "Children's Participation in a Virtual Epidemic in the Science Classroom: Making Connections to Natural Infectious Diseases," Journal of Science Education and Technology, vol. 16, p. 47, 2006/11/23 2006. https://doi.org/10.1007/s10956-006-9029-Z

[42] C. Shi, L. Wang, X. Li, S. Chai, W. Niu, Y. Kong, et al., "Virtual classroom helps medical education for both Chinese and foreign students," European Journal of Dental Education, vol. 19, pp. 217-221, 2015. https://doi.org/10.1111/eje.12124

[43] R. C. Chick, G. T. Clifton, K. M. Peace, B. W. Propper, D. F. Hale, A. A. Alseidi, et al., "Using Technology to Maintain the Education of Residents During the COVID-19 Pandemic," Journal of Surgical Education, 2020/04/03/ 2020. https://doi.org/10.1016/j.j surg.2020.03.018

[44] E. A. Becker and C. C. Gibson, "Fishbein and Ajzen's Theory of Reasoned Action: Accurate Prediction of Behavioral Intentions for Enrolling in Distance Education Courses," Adult Education Quarterly, vol. 49, pp. 43-55, 1998. https://doi.org/10.1177/074 171369804900105

[45] H. Thinyane, T. K. Mufeti, A. Terzoli, and M. Wright, "Google docs and skype for a low bandwidth virtual classroom for developing countries," in 2010 IST-Africa, 2010, pp. 1-7. 
[46] C. A. Tuttas, "Lessons learned using web conference technology for online focus group interviews," Qualitative Health Research, vol. 25, pp. 122-133, 2015. https://doi.org/10.11 77/1049732314549602

[47] S. Weller, "Using internet video calls in qualitative (longitudinal) interviews: Some implications for rapport," International Journal of Social Research Methodology, vol. 20, pp. 613-625, 2017. https://doi.org/10.1080/13645579.2016.1269505

[48] N. Levak and J.-B. Son, "Facilitating second language learners' listening comprehension with Second Life and Skype," ReCALL, vol. 29, pp. 200-218, 2017. https://doi.org/10.101 7/s0958344016000215

[49] S. Taylor and P. A. Todd, "Understanding information technology usage: A test of competing models," Information systems research, vol. 6, pp. 144-176, 1995. https://doi. org/10.1287/isre.6.2.144

[50] H. Ajjan and R. Hartshorne, "Investigating faculty decisions to adopt Web 2.0 technologies: Theory and empirical tests," The internet and higher education, vol. 11, pp. 71-80, 2008. https://doi.org/10.1016/j.iheduc.2008.05.002

[51] L. Garay, X. Font, and A. Corrons, "Sustainability-oriented innovation in tourism: An analysis based on the decomposed theory of planned behavior," Journal of Travel Research, vol. 58, pp. 622-636, 2019. https://doi.org/10.1177/0047287518771215

[52] B. W. Pryor, "Predicting and Explaining Intentions to Participate in Continuing Education: An Application of the Theory of Reasoned Action," Adult Education Quarterly, vol. 40, pp. 146-157, 1990. https://doi.org/10.1177/0001848190040003003

[53] C. Gotch and T. Hall, "Understanding nature-related behaviors among children through a theory of reasoned action approach," Environmental Education Research, vol. 10, pp. 157177, 2004/05/01 2004. https://doi.org/10.1080/13504620242000198159

[54] P. Sheldon, "Facebook friend request: Applying the theory of reasoned action to studentteacher relationships on Facebook," Journal of Broadcasting \& Electronic Media, vol. 60, pp. 269-285, 2016. https://doi.org/10.1080/08838151.2016.1164167

[55] T. Ramayah, "Students' choice intention of a higher learning institution: An application of the theory of reasoned action (TRA)," Malaysian Management Journal, vol. 7, pp. 47-62, 2020. https://doi.org/10.32890/mmj.7.1.2003.8603

[56] Y. K. Usluel and S. G. Mazman, "Adoption of Web 2.0 tools in distance education," Procedia-Social and Behavioral Sciences, vol. 1, pp. 818-823, 2009. https://doi.org/10.10 16/j.sbspro.2009.01.146

[57] O. F. Al-Kurdi, R. El-Haddadeh, and T. Eldabi, "The role of organisational climate in managing knowledge sharing among academics in higher education," International Journal of Information Management, vol. 50, pp. 217-227, 2020/02/01/ 2020. https://doi.org/10.10 16/j.ijinfomgt.2019.05.018

[58] D. E. Montano and D. Kasprzyk, "Theory of reasoned action, theory of planned behavior, and the integrated behavioral model," Health behavior: Theory, research and practice, vol. 70, p. 231, 2015.

[59] I. Ajzen, "Perceived behavioral control, self-efficacy, locus of control, and the theory of planned behavior 1," Journal of applied social psychology, vol. 32, pp. 665-683, 2002. https://doi.org/10.1111/j.1559-1816.2002.tb00236.x

[60] N. N. Long and B. H. Khoi, "An Empirical Study about the Intention to Hoard Food during COVID-19 Pandemic," EURASIA Journal of Mathematics, Science and Technology Education, vol. 16, p. em1857, 2020. https://doi.org/10.29333/ejmste/8207

[61] C. Shao and K. H. Kwon, "Clicks intended: An integrated model for nuanced social feedback system uses on Facebook," Telematics and Informatics, vol. 39, pp. 11-24, 2019. https://doi.org/10.1016/j.tele.2018.12.003

[62] F. Aburub and I. Alnawas, "A new integrated model to explore factors that influence adoption of mobile learning in higher education: An empirical investigation," Education 
and Information Technologies, vol. 24, pp. 2145-2158, 2019. https://doi.org/10.1007/s1063 9-019-09862-x

[63] C. Haas, "Coronavirus and Risk Analysis," Risk Analysis, vol. n/a, 2020.

[64] M. Douglas and A. Wildavsky, Risk and culture: An essay on the selection of technological and environmental dangers: Univ of California Press, 1983. https://doi.org/ $10.1525 / 9780520907393$

[65] H. Insights, "NATIONAL CULTURE," 2019.

[66] A. Wildavsky and K. Dake, "Theories of risk perception: Who fears what and why?," Daedalus, pp. 41-60, 1990.

[67] S. Oltedal, B.-E. Moen, H. Klempe, and T. Rundmo, "Explaining risk perception: An evaluation of cultural theory," Trondheim: Norwegian University of Science and Technology, vol. 85, p. 86, 2004.

[68] G. R. Dowling and R. Staelin, "A model of perceived risk and intended risk-handling activity," Journal of consumer research, vol. 21, pp. 119-134, 1994. https://doi.org/10.10 $\underline{86 / 209386}$

[69] A. Y. Lo, "The role of social norms in climate adaptation: Mediating risk perception and flood insurance purchase," Global Environmental Change, vol. 23, pp. 1249-1257, 2013. https://doi.org/10.1016/j.gloenvcha.2013.07.019

[70] A. Lobb, M. Mazzocchi, and W. Traill, "Modelling risk perception and trust in food safety information within the theory of planned behaviour," Food quality and preference, vol. 18, pp. 384-395, 2007. https://doi.org/10.1016/j.foodqual.2006.04.004

[71] J. Kozup, "Risks of Consumer Products," in Consumer Perception of Product Risks and Benefits, ed: Springer, 2017, pp. 23-38. https://doi.org/10.1007/978-3-319-50530-5_2

[72] J. Jacoby and L. B. Kaplan, "The components of perceived risk," ACR Special Volumes, 1972.

[73] R. A. Bauer, "Consumer behavior as risk taking," Chicago, IL, pp. 384-398, 1960.

[74] D. F. Cox and S. U. Rich, "Perceived risk and consumer decision-making - the case of telephone shopping," Journal of marketing research, vol. 1, pp. 32-39, 1964. https://doi. org/10.1177/002224376400100405

[75] P. Ulleberg and T. Rundmo, "Personality, attitudes and risk perception as predictors of risky driving behaviour among young drivers," Safety science, vol. 41, pp. 427-443, 2003. https://doi.org/10.1016/s0925-7535(01)00077-7

[76] R. M. Anderson, H. Heesterbeek, D. Klinkenberg, and T. D. Hollingsworth, "How will country-based mitigation measures influence the course of the COVID-19 epidemic?," The Lancet, vol. 395, pp. 931-934, 2020. https://doi.org/10.1016/s0140-6736(20)30567-5

[77] S. K. Brooks, R. K. Webster, L. E. Smith, L. Woodland, S. Wessely, N. Greenberg, et al., "The psychological impact of quarantine and how to reduce it: rapid review of the evidence," The Lancet, vol. 395, pp. 912-920, 2020/03/14/ 2020. https://doi.org/10.1016/s0 140-6736(20)30460-8

[78] X. Liu, J. Liu, S. Zhu, W. Wang, and X. Zhang, "Privacy risk analysis and mitigation of analytics libraries in the android ecosystem," IEEE Transactions on Mobile Computing, 2019.

[79] F. Hofmann, C. Ferracin, G. Marsh, and R. Dumas, "Influenza vaccination of healthcare workers: a literature review of attitudes and beliefs," Infection, vol. 34, pp. 142-147, 2006. https://doi.org/10.1007/s15010-006-5109-5

[80] Y. Zhang, H. Yang, P. Cheng, and A. Luqman, "Predicting consumers' intention to consume poultry during an H7N9 emergency: an extension of the theory of planned behavior model," Human and Ecological Risk Assessment: An International Journal, vol. 26, pp. 190-211, 2020. https://doi.org/10.1080/10807039.2018.1503931

[81] V. A. Quintal, J. A. Lee, and G. N. Soutar, "Risk, uncertainty and the theory of planned behavior: A tourism example," Tourism management, vol. 31, pp. 797-805, 2010. https:// doi.org/10.1016/j.tourman.2009.08.006 
[82] S. McLeod, "Maslow's hierarchy of needs," Simply psychology, vol. 1, pp. 1-8, 2007.

[83] R. B. Cialdini and N. J. Goldstein, "Social influence: Compliance and conformity," Annu. Rev. Psychol., vol. 55, pp. 591-621, 2004. https://doi.org/10.1146/annurev.psych.55.0909 02.142015

[84] J. J. Van Bavel, P. Boggio, V. Capraro, A. Cichocka, M. Cikara, M. Crockett, et al. (2020). Using social and behavioural science to support COVID-19 pandemic response. Available: psyarxiv.com

[85] K. Alzahrani, A. Hall-Phillips, and A. Z. Zeng, "Applying the theory of reasoned action to understanding consumers' intention to adopt hybrid electric vehicles in Saudi Arabia," Transportation, vol. 46, pp. 199-215, 2019/02/01 2019. https://doi.org/10.1007/s11116017-9801-3

[86] H. Han, L.-T. J. Hsu, and C. Sheu, "Application of the theory of planned behavior to green hotel choice: Testing the effect of environmental friendly activities," Tourism management, vol. 31, pp. 325-334, 2010. https://doi.org/10.1016/j.tourman.2009.03.013

[87] F. Munoz-Leiva, S. Climent-Climent, and F. Liébana-Cabanillas, "Determinants of intention to use the mobile banking apps: An extension of the classic TAM model," Spanish Journal of Marketing-ESIC, vol. 21, pp. 25-38, 2017. https://doi.org/10.1016/j.sj me.2016.12.001

[88] G. Stefani, A. Cavicchi, D. Romano, and A. E. Lobb, "Determinants of intention to purchase chicken in Italy: the role of consumer risk perception and trust in different information sources," Agribusiness: An International Journal, vol. 24, pp. 523-537, 2008. https://doi.org/10.1002/agr.20177

[89] J.-B. Lohmöller, Latent variable path modeling with partial least squares: Springer Science \& Business Media, 2013. https://doi.org/10.1007/978-3-642-52512-4

[90] V. E. Vinzi, W. W. Chin, J. Henseler, and H. Wang, Handbook of partial least squares vol. 201: Springer, 2010. https://doi.org/10.1007/978-3-540-32827-8_1

[91] M. Klesel, F. Schuberth, J. Henseler, and B. Niehaves, "A test for multigroup comparison using partial least squares path modeling," Internet research, vol. 29, pp. 464-477, 2019. https://doi.org/10.1108/intr-11-2017-0418

[92] J. F. Hair Jr, G. T. M. Hult, C. Ringle, and M. Sarstedt, A primer on partial least squares structural equation modeling (PLS-SEM): Sage Publications, 2016. https://doi.org/10.39 26/oss. 37

[93] J. C. Nunnally and I. Bernstein, "The assessment of reliability," Psychometric theory, vol. 3, pp. 248-292, 1994.

[94] J. Henseler, G. Hubona, and P. A. Ray, "Using PLS path modeling in new technology research: updated guidelines," Industrial management \& data systems, vol. 116, pp. 2-20, 2016. https://doi.org/10.1108/imds-09-2015-0382

[95] L.-t. Hu and P. M. Bentler, "Fit indices in covariance structure modeling: Sensitivity to underparameterized model misspecification," Psychological methods, vol. 3, p. 424, 1998. https://doi.org/10.1037/1082-989x.3.4.424

\section{$7 \quad$ Authors}

Nguyen Ngoc Long works at Industrial University of Ho Chi Minh City in Vietnam. nguyenngoclong@iuh.edu.vn

Bui Huy Khoi works at Industrial University of Ho Chi Minh City in Vietnam.

Article submitted 2020-07-02. Resubmitted 2020-08-03. Final acceptance 2020-08-03. Final version published as submitted by the authors. 